\title{
The role of calsenilin/DREAM/KChIP3 in contextual fear conditioning
}

\author{
Jon C. Alexander, ${ }^{1,2}$ Carmel M. McDermott, ${ }^{3}$ Tumay Tunur, ${ }^{3}$ Vicky Rands, ${ }^{4}$ \\ Claire Stelly, ${ }^{3}$ Debra Karhson, ${ }^{1}$ Mark R. Bowlby, ${ }^{5}$ W. Frank An, ${ }^{6}$ J. David Sweatt, ${ }^{2}$ \\ and Laura A. Schrader ${ }^{3,7}$ \\ ${ }^{1}$ Department of Neuroscience, Baylor College of Medicine, Houston, Texas 77030, USA; ${ }^{2}$ Department of Neurobiology, University \\ of Alabama at Birmingham, Birmingham, Alabama 35294, USA; ${ }^{3}$ Department of Cell and Molecular Biology, Tulane University, \\ New Orleans, Louisiana 70118, USA; ${ }^{4}$ Department of Physiology, Tulane University, New Orleans, Louisiana 70118, USA; \\ ${ }^{5}$ Discovery Neuroscience, Wyeth Research, Princeton, New Jersey 08543, USA; ${ }^{6}$ Broad Institute of Harvard and MIT, Boston, \\ Massachusetts 02142, USA
}

\begin{abstract}
Potassium channel interacting proteins (KChIPs) are members of a family of calcium binding proteins that interact with Kv4 potassium $\left(\mathrm{K}^{+}\right)$channel primary subunits and also act as transcription factors. The Kv4 subunit is a primary $\mathrm{K}^{+}$ channel pore-forming subunit, which contributes to the somatic and dendritic A-type currents throughout the nervous system. These A-type currents play a key role in the regulation of neuronal excitability and dendritic processing of incoming synaptic information. KChIP3 is also known as calsenilin and as the transcription factor, downstream regulatory element antagonist modulator (DREAM), which regulates a number of genes including prodynorphin. KChIP3 and Kv4 primary channel subunits are highly expressed in hippocampus, an area of the brain important for learning and memory. Through its various functions, KChIP3 may play a role in the regulation of synaptic plasticity and learning and memory. We evaluated the role of KChIP3 in a hippocampus-dependent memory task, contextual fear conditioning. Male KChIP3 knockout (KO) mice showed significantly enhanced memory 24 hours after training as measured by percent freezing. In addition, we found that membrane association and interaction with Kv4.2 of KChIP3 protein was significantly decreased and nuclear KChIP3 expression was increased six hours after the fear conditioning training paradigm with no significant change in KChIP3 mRNA. In addition, prodynorphin mRNA expression was significantly decreased six hours after fear conditioning training in wild-type (WT) but not in KO animals. These data suggest a role for regulation of gene expression by KChIP3/DREAM/calsenilin in consolidation of contextual fear conditioning memories.
\end{abstract}

Theories of Hebbian-type synaptic plasticity propose that strengthening of synaptic connections is dependent on coincident activity in pre- and postsynaptic neurons. Research has focused on regulation of transmitter release and receptor function at the synapse; however, changes in neuronal excitability during learning processes have received less attention. Modulation of postsynaptic excitability, via regulation of ion channels, is another possible mechanism for modification of the threshold for induction of synaptic plasticity. Transient outward or A-type currents are generally responsible for regulation of both neuronal excitability and the inter-spike interval in neurons in both vertebrate and invertebrate systems. A-type currents control action potential broadening, back-propagating action potentials in CA1 pyramidal cells, and are regulated by neuromodulators and long-term potentiation (LTP) (Hoffman et al. 1997; Hoffman and Johnston 1998; Yuan et al. 2002; Frick et al. 2004; Kim et al. 2005).

Modulation of back-propagating action potentials by the A-type current is a mechanism that could have dramatic effects on regulation of synaptic strength, particularly during associative plasticity. Recent studies demonstrated that the A-type current in CA1 pyramidal cell dendrites is mediated by the Kv4.2 subunit

\footnotetext{
${ }^{7}$ Corresponding author.
}

E-mail schrader@tulane.edu; fax (504) 865-6785.

Article is online at http://www.learnmem.org/cgi/doi/10.1101//m.1261709.
(Chen et al. 2006) and that Kv4.2 surface expression is decreased by LTP-inducing stimuli (Kim et al. 2007). This suggests that rapid remodeling of the subunits that underlie the A-type current during activity-dependent processes can enhance the induction of plasticity.

Kv4 surface expression and currents are modulated by KChIP (potassium channel interacting protein) and DPPX expression (Birnbaum et al. 2004; Jerng et al. 2005). Four subtypes of KChIPs (1-4) are described to date, and 12 splice variants currently exist (An et al. 2000; Holmqvist et al. 2002; Morohashi et al. 2002; Boland et al. 2003; Van Hoorick et al. 2003). These proteins bind specifically to the N-terminal of Kv4 primary subunits (Scannevin et al. 2004; Zhou et al. 2004) and form octomeric structures with four primary subunits (Kv4) and four KChIP subunits forming a channel (Kim et al. 2004). The KChIPs co-localize and coimmunoprecipitate with brain $\mathrm{Kv} 4$ subunits and thus are integral components of the native A-type current complexes (An et al. 2000). Co-expression of the KChIPs and Kv4 subunits in heterologous cells increases the current density, slows inactivation kinetics, and increases the rate of recovery from inactivation of the Kv4 channels (An et al. 2000; Bahring et al. 2001; Holmqvist et al. 2002; Patel et al. 2002, 2004; Schrader et al. 2002; Shibata et al. 2003). The KChIPs also possess four EF-hand-like domains, three of which bind calcium ions (Burgoyne and Weiss 2001). The $\mathrm{Ca}^{2+}$-binding properties of the KChIPs make them intriguing subjects to study with reference to activity-dependent plasticity, 
as in most cases an increase in calcium in the postsynaptic cell is an initial step in changes of synaptic efficacy.

KChIP3 was originally isolated as a presenilin (PS)-interacting protein and is also known as calsenilin (Buxbaum et al. 1998; Zaidi et al. 2002) and later described with 99\% homology with DREAM (downstream regulatory element antagonist modulator), a $\mathrm{Ca}^{2+}$-regulated transcriptional repressor (Carrion et al. 1999). KChIP3 is strongly expressed in the hippocampus, specifically the dentate gyrus (DG), and its expression overlaps at the cellular and subcellular localization with $\mathrm{Kv} 4$ subunits and presenilin (Lilliehook et al. 2003; Rhodes et al. 2004). Moreover, the dentate granule cells of KChIP3 knockout (KO) mice exhibit slightly reduced A-type current; consistent with this observation LTP magnitude at perforant path-dentate granule cell synapses is enhanced in KChIP3 KO mice (Lilliehook et al. 2003). Together, these data suggest that KChIP3 may play a role in learning and memory. In this study, we investigated the role of KChIP3 in hippocampus-dependent contextual fear memory using a mouse genetic engineering approach.

\section{Results}

Expression of related proteins in KChIP3 $\mathrm{KO}$ animals

All mice used in this study were genotyped using polymerase chain reaction (PCR), and $\mathrm{KO}$ genotype was confirmed by Western blot analysis, i.e., lack of a KChIP3 band in the hippocampus (Fig. 1). In previous experiments $\mathrm{Kv} 4.2 \mathrm{KO}$ mice showed cell-specific decreased expression of KChIPs 1-3 in the hippocampus (Chen et al. 2006; Menegola and Trimmer 2006), therefore we determined if there was a reciprocal regulation of $\mathrm{Kv} 4$ or other KChIPs in the KChIP3 KO mice. Western blot analysis of total hippocampus with the respective antibodies (see Materials and Methods) showed that the levels of these proteins were not significantly altered (Fig. 1B). We found no significant difference in the levels of KChIP1 $\left(\mathrm{KO} n=4,118 \pm 27 \%\right.$ of WT $n=3,100 \pm 32 \% ; t_{(5)}=0.44$, $P=0.68)$ or KChIP2 (KO $n=6,79 \pm 13 \%$ of WT $n=5,100 \pm 12 \%$; $\left.t_{(9)}=1.2, P=0.28\right)$ as well as $\mathrm{Kv} 4.2(\mathrm{KO} n=10,119 \pm 14 \%$ of WT $\left.n=8,100 \pm 10 \% ; t_{(16)}=0.97, P=0.35\right)$ and $\mathrm{Kv} 4.3(\mathrm{KO} n=5,85 \pm$ $13 \%$ of WT $n=5,100 \pm 16 \% ; t_{(8)}=0.73, P=0.49$ ). This suggests that lack of the KChIP3 gene does not cause significantly altered regulation of protein expression of Kv4.2, Kv4.3, KChIP2, or KChIP1 in the hippocampus and that these mice exhibit normal levels of these proteins.

\section{Behavioral analysis}

We performed several behavioral tests to assess locomotor activity, foot shock response, and anxiety in the male KChIP3 KO vs. WT mice. KChIP3 KO mice showed no difference from WT mice in the accelerating rotarod task (Fig. 2A). Mice were tested over $2 \mathrm{~d}$ with four trials per day. There was no significant effect of genotype over trials $\left(F_{(1,147)}=1.24 ; P=0.28 ; \mathrm{KO} n=15\right.$; WT $n=8$; Repeated Measures ANOVA). This suggests that KChIP3 KO mice perform comparable to WT mice on a test of motor coordination and motor learning.

A previous report showed that KChIP3 KO mice exhibit decreased sensitivity to pain (Cheng et al. 2002). Since the fearconditioning test uses a mild foot shock as the unconditioned stimulus, we compared foot shock sensitivity in WT and KO mice. Mice were tested for foot shock response at differing intensities to be sure that any alterations in memory were not due to changes in sensitivity to the foot shock (see Materials and Methods for details). There was no significant difference in the response of the KO mice compared to the WT mice at any of the intensity levels tested $(0.1-0.7 \mathrm{~mA})\left(F_{(1,85)}=0.02, P=0.88 ; \mathrm{WT} n=10 ; \mathrm{KO} n=\right.$ 10; Repeated Measures ANOVA; Fig. 2B). This suggests that any
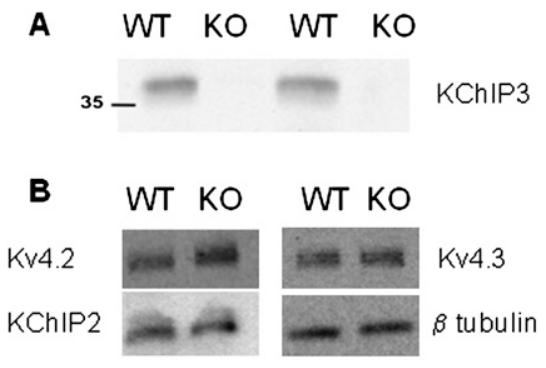

C Protein expression

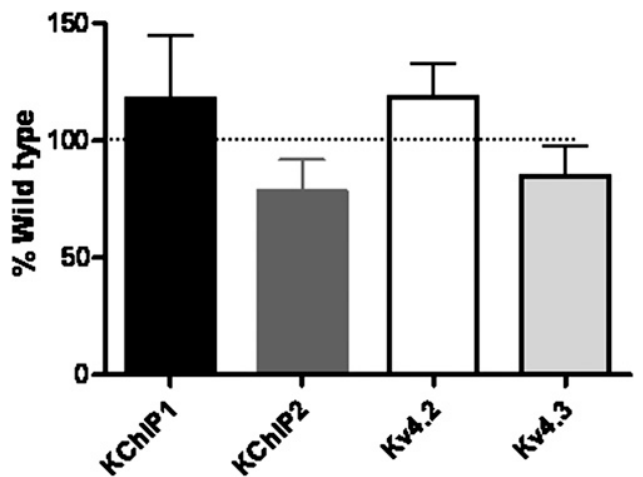

Figure 1. Analysis of immunoreactivity for expression levels of relevant proteins in KChIP3 KO mice. (A) Western blotting was used to confirm genotyping in KChIP3 KO and WT littermate mice. The presence of a KChIP3 band indicated WT while the absence of a band indicated KChIP3 KO. (B) Representative Western blots for Kv4.2, Kv4.3, KChIP2, and $\beta$ tubulin, which was used as a loading control. (C) Bar graph summary of immunoreactivity of protein expression levels in $\mathrm{KO}$ relative to WT of KChIP1 (KO $n=4$; WT $n=3), \mathrm{KChIP2}(\mathrm{KO} n=6, \mathrm{WT} n=5), \mathrm{Kv} 4.2$ (KO $n=10, \mathrm{WT} n=8)$, and $\mathrm{Kv} 4.3(\mathrm{KO} n=5, \mathrm{WT} n=5)$. There were no significant differences between WT and KO expression levels of any of the proteins assayed $(P>0.05, t$-test).

behavioral effects in the fear-conditioning paradigm are not due to a differential sensitivity to shock threshold in the KChIP3 KO mice. A lack of difference in mild foot shock sensitivity in KChIP3 $\mathrm{KO}$ mice is not surprising even though these animals were reported to have alterations in pain sensitivity (Cheng et al. 2002) because the foot shock intensities utilized in fear-conditioning paradigms are deliberately chosen to be aversive yet not painful in order to assure learning.

The KChIP3 KO mice were also tested in the open field assay (OFA) (Weiss et al. 2000) and elevated plus maze (EPM) to determine baseline locomotor activity and anxiety levels (Itoh et al. 1991; Kulkarni and Sharma 1991). The total exploratory activity in the OFA exhibited by the KChIP3 KO mice was decreased but not significantly different compared to WT mice (WT, $n=16,1416 \pm 184 \mathrm{~cm} ; \mathrm{KO}, n=11,1041 \pm 245 \mathrm{~cm}, t_{(25)}=1.3$, $P=0.22$; Fig. $3 \mathrm{~A}$ ). Furthermore, the center distance exploration was decreased but not significantly different between the WT and KO mice (WT, $208 \pm 42 \mathrm{~cm}$ vs. $\mathrm{KO}, 105 \pm 31 \mathrm{~cm} ; t_{(25)}=1.8, P=$ 0.08; Fig. 3A). Similarly, the center/total distance ratio was decreased in KChIP3 KO mice as compared to WT, but the difference was not significant (WT $0.13 \pm 0.02$ vs. KO $0.09 \pm 0.01 ; t_{(25)}=1.6$, $P=0.13$; Fig. 3B). We also tested a subset of these animals in the EPM (Fig. 3C). There was no significant difference between WT and KChIP3 KO mice in percent time spent in the open arms of the EPM (Fig. 3C; KO, $n=6 ; 8 \pm 7 \%$; WT, $n=10 ; 9 \pm 3 \% ; t_{(14)}=0.09, P=$ 0.93 ) or crossings into the open arms (Fig. 3D; KO, $n=6 ; 2.8 \pm 1.4$; WT, $\left.n=10 ; 6.4 \pm 1.8, t_{(14)}=1.4, P=0.18\right)$. Overall, these data 

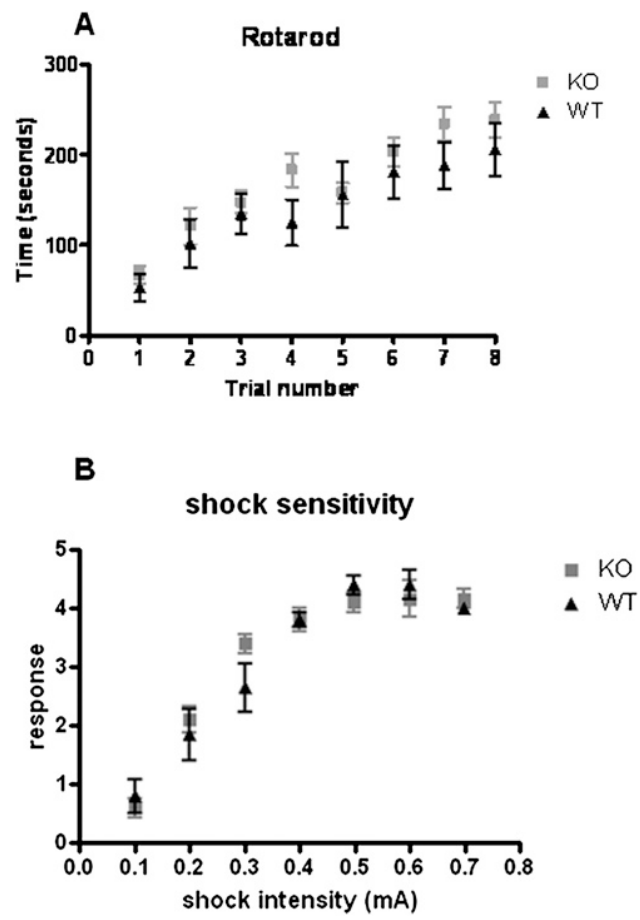

Figure 2. KChIP3 KO mice exhibit normal locomotor activity and shock sensitivity. (A) The accelerating rotarod task was used to assess motor learning and coordination in KChIP3 KO and WT littermate mice. Mice were trained four trials a day for $2 \mathrm{~d}$ for a total of eight trials, and time spent on the rod per trial was averaged across genotype and plotted per trial. No significant effect of genotype over trials was observed (KO $n=15$; WT $n=8$; Repeated Measures ANOVA; $P=0.28$ ). (B) Response to foot shock in WT and KO mice. KChIP3 KO $(n=10)$ and WT littermate mice $(n=$ 10) were tested for foot shock responses (see Materials and Methods) at increasing intensities (0.1-0.7 mA in 0.1 increments). There were no significant differences in the responses of the KChIP3 KO mice compared to WT littermates $(P>0.05$, Repeated Measures ANOVA).

suggest that the KChIP3 KO mice may have slightly increased anxiety compared to the WT littermate controls, however, the differences were not significant.

\section{Cued and contextual fear conditioning}

Several properties of KChIP3 suggest that it may play a role in learning and memory. First, it is a $\mathrm{Ca}^{2+}$-regulated transcriptional repressor through its role as DREAM (Carrion et al. 1999). Secondly, KChIP3 is known to regulate Kv4.x surface expression and kinetics (Birnbaum et al. 2004). Finally, LTP is enhanced at the perforant path-dentate granule cell synapse in KChIP3 KO mice (Lilliehook et al. 2003). Therefore, we wished to determine if KChIP3 might regulate long-term memory formation, using a cued and contextual fear-conditioning paradigm. We tested the memory in KChIP3 KO animals and WT littermate controls for contextual and cued fear conditioning $24 \mathrm{~h}$ after training. Mice were trained on day 1 with a single shock (see Materials and Methods). Male KChIP3 KO and WT showed no differences on the training day in freezing during the exploration period before the tone, during the tone (black bar), or after the foot shock (Fig. 4A, arrow, $0.5 \mathrm{~mA}, 2 \mathrm{sec}$ ). Moreover, there was no significant difference between WT and KChIP3 KO mice in the cued fearconditioning paradigm (Fig. 4B; WT $80 \pm 5, n=6$; KO $85 \pm 4 \%$, $\left.n=7, t_{(11)}=0.792, P=0.4467\right)$. This suggests that the KChIP3 KO animals exhibit normal exploration activity and amygdaladependent fear conditioning, and that they are able to exhibit normal freezing behavior.
The mice were also tested in the contextual fear-conditioning paradigm. In the contextual fear-conditioning paradigm, KChIP3 KO mice showed a significant enhancement of freezing behavior when tested at $24 \mathrm{~h}$ after training (Fig. 4C; WT $28 \pm 5 \%, n=11$; vs. KO $\left.60 \pm 7 \%, n=10, t_{(19)}=3.54, P=0.002\right)$. This effect was longlasting as KChIP3 KO mice re-exposed to the box one month after training also showed enhanced freezing compared to WT mice (WT $11 \pm 4 \%, n=7$; KO $31 \pm 6 \%, n=5, t_{(10)}=0.3 .233, P=0.009$ ).

As described above, the results from the anxiety tests showed that the KChIP3 KO mice exhibited slightly enhanced anxiety relative to WT animals. Increased anxiety could be a possible explanation for the enhanced freezing behavior in the context test after the foot shock. Two points argue against this possibility: (1) The KChIP3 KO and WT mice exhibit similar baseline activity on training day at all time points: before the tone, during tone exposure, and after the foot shock (Fig. 4A); and (2) there was no significant difference in the cued test between WT and KO mice.

To be certain that the increased anxiety did not play a role in the post-shock enhanced performance in the contextual test in the KChIP3 KO mice, we tested another group of animals $1 \mathrm{~h}$ after training on both the cued and contextual tests (Fig. 5). One hour after training, KChIP3 $\mathrm{KO}$ mice froze at the same level as the WT animals in both the contextual (Fig. 5A; KChIP3 KO, $n=4,35 \pm$ $16 \%$ vs. WT $\left.n=8,36 \pm 11 \% ; t_{(10)}=0.04, P=0.9725\right)$ and cued fearconditioning tests (Fig. 5B; KChIP3 KO, $n=4,73 \pm 18 \%$ vs. WT $\left.n=8,77 \pm 10 \% ; t_{(10)}=0.9, P=0.85\right)$. Together with the 24-h contextual test, these data suggest that KChIP3 may reduce consolidation of hippocampus-dependent contextual memory. Furthermore, this effect was long-lasting as the KO mice exhibited enhanced freezing when re-exposed to the training context one month later.

\section{Mechanism of enhanced contextual memory}

We wished to further investigate the role that KChIP3 plays in fear conditioning. We hypothesized that KChIP3 may act through its role as a Kv4 channel interacting protein (An et al. 2000) or through its role as a transcriptional repressor (Carrion et al. 1999). Therefore, we used Western blot analysis to study changes in KChIP3 localization (membrane association or localization in the nucleus) in the hippocampus after fear-conditioning training. We determined the membrane association and nuclear expression of KChIP3 and membrane expression of Kv4.2 in the hippocampus at different time points after fear-conditioning training (Fig. 6). KChIP3 expression was investigated in the cytosolic fraction; however, no detectable KChIP3 immunoreactivity was found in this fraction, therefore we did not investigate the cytosolic fraction further. This suggests that detectable KChIP3 protein is either localized in membrane or nuclear fractions. Furthermore, the immunoreactivity for KChIP3 in the membrane fraction was much higher than the nuclear expression making relative comparison amounts inaccurate. Therefore, we did not compare membrane and nuclear expression levels.

Circadian fluctuations in the expression of KChIP3 were previously reported in the retina and pineal gland (Link et al. 2004). For this reason, we tested three groups of animals at each time point. These groups included: fear-conditioning trained animals (FC), animals that were placed in the same context for the same amount of time but not trained (CXT), and animals that received latent inhibition training (LI) (see Materials and Methods). LI-trained animals do not learn to associate the context with the foot shock (Levenson et al. 2004), and therefore serve as a control for the associative learning. At each time point $(1,6$, and $24 \mathrm{~h}$ after removal from the chamber) FC and LI were normalized to CXT as the control.

Figure 6A-C and Table 1 show the results of these experiments. One hour after training, KChIP3 membrane association in 
A

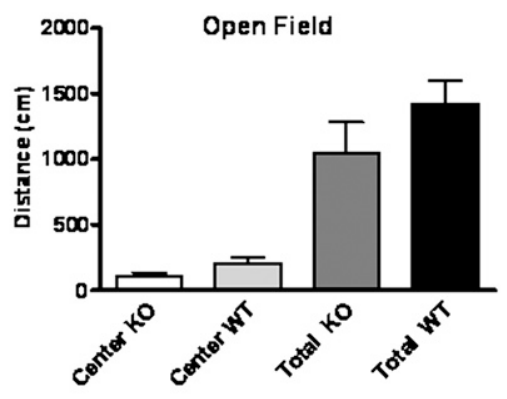

B

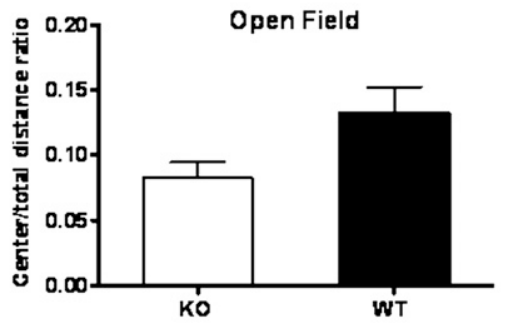

C

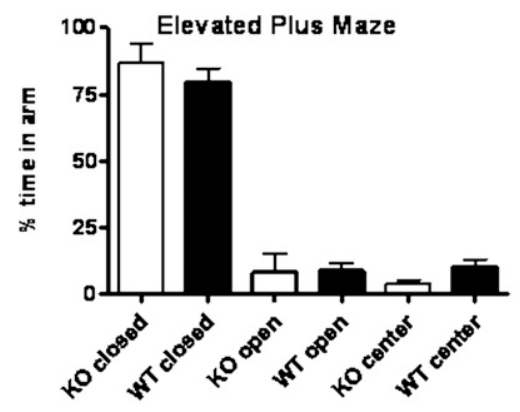

D

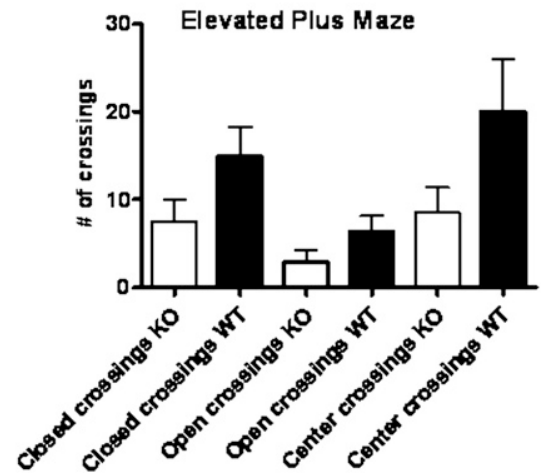

Figure 3. Open field and elevated plus maze (EPM) performance in KChIP3 KO mice. KChIP3 KO and WT littermate mice were tested in the open field assay (OFA) to determine baseline locomotor activity and anxiety-like behavior. (A) Summary bar graph of exploratory activity of KChIP3 KO vs. WT mice in the OFA. Total exploratory activity and exploration of the center in the OFA exhibited by the KChIP3 KO mice $(n=11)$ was decreased but not significantly different compared to WT mice $(n=16 ; P>0.05, t$ test). (B) Bar graph representing the center/total distance ratio decreased in KChIP3 KO mice as compared to WT but not significantly different $(P>0.05$; $t$-test). (C) KChIP3 KO and WT littermate mice were also tested in the EPM. KChIP3 KO mice $(n=6)$ spent approximately the same amount of time in the open arms as did the WT littermates $(n=10)$. (D) Crossings into the open arms by KO mice were decreased compared to the WT animals, but the differences were not significant $(P>0.05 ; t$-test).

FC1 hippocampus was not significantly different from CXT1 but was significantly higher than LI1 (Fig. 6A,B; Table 1). KChIP3 membrane association was decreased $6 \mathrm{~h}$ after FC and LI training relative to CXT6 (Fig. 6A,B; Table 1). Furthermore, KChIP3 membrane expression $6 \mathrm{~h}$ after FC and LI were not significantly different from each other. No significant differences in KChIP3 membrane expression were found at the $24 \mathrm{~h}$ time point between any of the groups of animals (Fig. 6A,B; Table 1). There was also no significant effect on total $\mathrm{Kv} 4.2$ membrane expression at any of the time points (Fig. 6A,C; Table 2). These data suggest that KChIP3 membrane association is decreased $6 \mathrm{~h}$ after training relative to CXT, but Kv4.2 membrane expression is not regulated after fear conditioning.

\section{Mechanisms of decreased levels of KChIP3 protein}

We were interested to determine whether changes in transcription of KChIP3 mRNA may contribute to the decrease of KChIP3 protein associated with the membrane. Therefore, we performed real-time PCR experiments to study KChIP3 mRNA expression. Similar to the protein expression, we normalized mRNA levels in $\mathrm{LI}$ and FC to CXT at each time point. There were no differences in KChIP3 mRNA expression at any of the time points between CXT, FC, and LI (Fig. 6D); 1 -h time point $\left(F_{(2,7)}=1.78, P=0.24 ; \mathrm{FC} 1, n=\right.$ $3,147 \pm 35 \%$; LI1, $n=3,138 \pm 15 \%), 6$-h time point $\left(F_{(2,11)}=0.53\right.$; $P=0.6$; FC6, $100 \pm 30 \%, n=5$; LI6, $n=5,73 \pm 18 \%$ ), and 24 -h time point $\left(F_{(2,7)}=1.47, P=0.29 ; \mathrm{FC} 24, n=3,77 \pm 20 \%, \mathrm{LI} 24, n=3,79 \pm\right.$
9\%). These data suggest that the changes in membrane KChIP3 protein expression are not mediated by changes in KChIP3 mRNA levels.

\section{$\mathrm{Kv} 4.2 / \mathrm{KChIP3}$ interaction}

This result led us to the hypothesis that the reduction of $\mathrm{KChIP3}$ membrane association may reduce the $\mathrm{Kv} 4.2 / \mathrm{KChIP} 3$ interaction. Therefore, we performed coimmunoprecipitation experiments (co-IP) using the KChIP3 antibody to investigate interactions with Kv4.2 (Fig. 7). As expected, there was no significant difference in $\mathrm{Kv} 4.2$ membrane expression between CXT and FC trained at the 6-h time point (FC6 $=98 \pm 15 \%$ of CXT6, $n=$ 3 ; input and bar graph in Fig. 7B); however, the Kv4.2 interaction with KChIP3 in the FC6-trained tissue was absent compared to the CXT6-trained tissue (IP KChIP3). We did not find any interaction of KChIP3 and Kv4.3 when the blots were probed with the Kv4.3 antibody, but we should note that we found less Kv4.3 antibody immunoreactivity in hippocampus. This suggests that the functional down-regulation of KChIP3 membrane association is related to a decreased interaction of Kv4.2 and KChIP3.

\section{Nuclear localization}

Since KChIP3 acts as a transcription factor, another possibility is that it may also translocate from the membrane to the nucleus at the 6-h time point. Therefore, we assayed nuclear fractions for the presence of KChIP3 antibody in the nucleus. We found that the KChIP3 antibody recognized a specific band in the nuclear fraction that was slightly smaller than the membrane KChIP3 band $(\sim 25 \mathrm{kDa})$ and was not present in the $\mathrm{KO}$ nuclear fraction (data not shown). This band may be the large portion of the cleavage product of KChIP3 when cleaved by caspase 3 (Choi et al. 2003). This band increased in the nucleus at the 6-h time point in the FC-trained animals relative to CXT, but not in the LI animals $\left(F_{(2,6)}=16.1\right.$, LI $n=3,59 \pm 37 \%$, FC $n=3,198 \pm 20 \%, P<0.01$; Fig. $8)$. To be sure that the nuclear fraction was pure, we probed the nuclear fraction with $\mathrm{Kv} 4.2$ and enolase antibodies (data not shown). These antibodies did not recognize any bands in the nuclear fraction, suggesting that the nuclear fraction was not contaminated with membrane and cytosol, respectively. This suggests that this increase in nuclear expression of KChIP3 may be specific to the fear-conditioned animals and may play a transcriptional role after fear conditioning.

\section{Role as transcription factor}

Dynorphin, a prodynorphin-derived peptide, and activation of the $\kappa$ opioid receptors can modulate learning and memory. Since prodynorphin is regulated by KChIP3 in its function as the transcriptional repressor DREAM (Carrion et al. 1999), we wished to determine if prodynorphin mRNA expression was regulated after the fear-conditioning paradigm. The increased nuclear KChIP3 expression at the 6-h time point suggested that KChIP3 might act to function as a transcriptional repressor, eliciting a decrease in prodynorphin expression. Indeed prodynorphin 
A

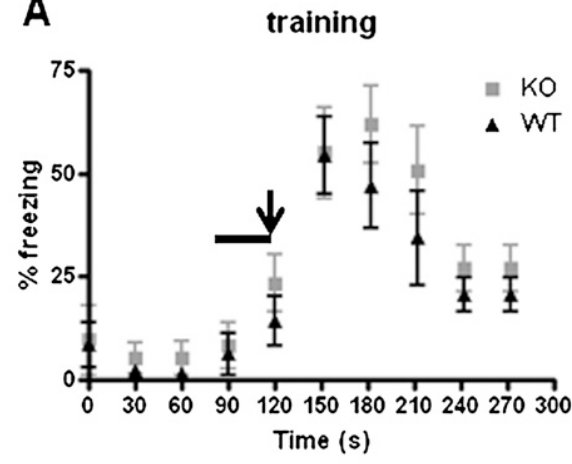

B

\section{Cued fe ar conditioning}
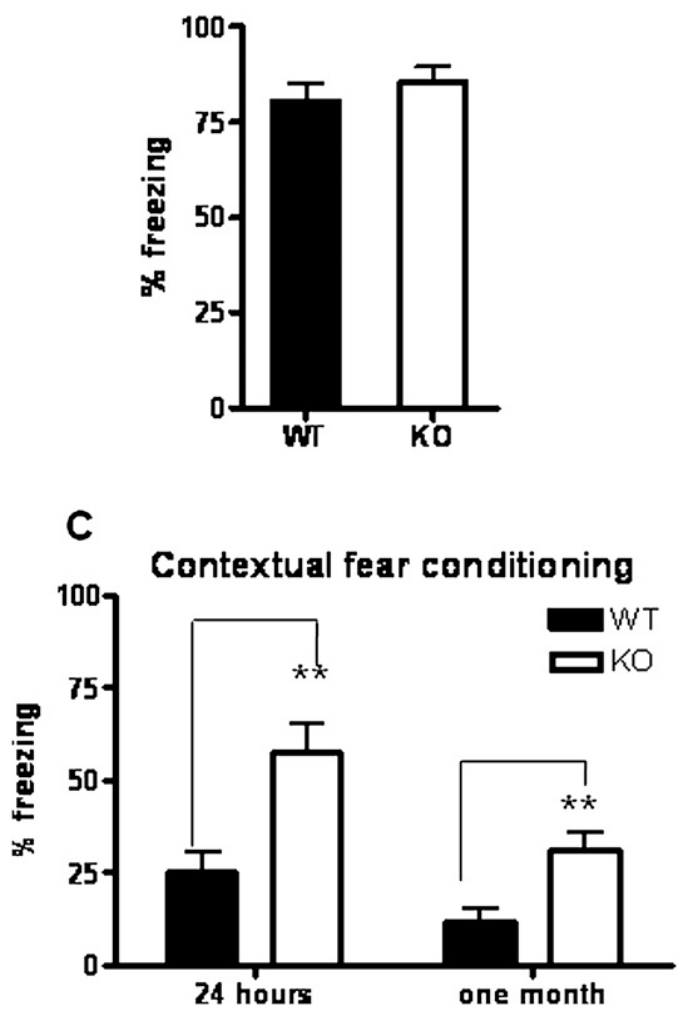

Figure 4. Male KChIP3 KO mice exhibit enhanced memory of contextual fear conditioning at $24 \mathrm{~h}$ and $1 \mathrm{mo}$. The fear memory of KChIP3 KO and WT littermate mice was tested using cued and contextual fear conditioning $24 \mathrm{~h}$ after training. (A) Mice were trained on day 1 using a single-shock protocol. There were no significant differences between KChIP3 KO and WT littermates in freezing on the training day during the exploration period before the tone, during the tone (black bar), or after the foot shock (arrow; $0.5 \mathrm{~mA}, 2 \mathrm{sec}$ ). (B) KChIP3 KO mice $(n=7)$ exhibited similar freezing compared to WT littermates in the cued test $(n=6$; $P>0.05, t$-test). (C) KChIP3 KO mice $(n=10)$ showed significantly increased freezing behavior to context compared to WT littermates $(n=$ 11 ) when tested at $24 \mathrm{~h}$ after training ( $t$-test; ** $P=0.002)$. This effect was long-lasting as KChIP3 KO mice $(n=5)$ re-exposed to the box one month after training also showed enhanced freezing compared to WT littermates $(n=7, t$-test; ** $P=0.009)$.

mRNA was significantly decreased at the 6-h time point compared to CXT6 in both FC6 and LI6 hippocampus $\left(F_{(2,14)}=6.9, P=0.008\right.$; FC6, $n=6,59 \pm 16 \%, P<0.05$, LI6, $n=6,47 \pm 12 \%, P<0.01)$. We found that prodynorphin mRNA was significantly increased at the 1-h time point in both FC1 and LI1 relative to CXT1 $\left(F_{(2,7)}=8.9, P=\right.$ 0.012 ; FC1, $n=3,142 \pm 15 \%, P<0.05$; LI $1, n=3,151 \pm 21 \% P<$ 0.05 ) and prodynorphin mRNA was decreased in both FC and LI at the 24-h time point, although not significantly (Fig. 9; $F_{(2,8)}=1.29$, $P=0.3279$, FC24, $n=3,71 \pm 25 \%$, LI $24, n=3,69 \pm 25 \%)$.

Many factors regulate prodynorphin mRNA expression; therefore, we wished to determine whether KChIP3 regulates prodynorphin mRNA expression in the hippocampus after training. We assessed whether prodynorphin mRNA is regulated in KChIP3 KO mice $6 \mathrm{~h}$ after fear conditioning. Prodynorphin mRNA was increased rather than decreased in the fear-conditioned $\mathrm{KO}$ hippocampus $(150 \pm 28 \%, n=6)$ compared to context-trained KO hippocampus $(P>0.05$; Fig. 9$)$. Prodynorphin mRNA was slightly, but not significantly, decreased in the context-trained $\mathrm{KO}$ relative to WT context-trained $(75 \pm 15 \%)$. Overall, these observations suggest that KChIP3 translocation away from the membrane and into the nucleus serves to regulate prodynorphin expression in long-term memory formation.

\section{Discussion}

The evidence presented here using KChIP3 KO mice indicates that KChIP3/calsenilin/DREAM plays a role in hippocampus-dependent memory. KChIP3 is highly expressed in the hippocampus, specifically the dentate gyrus (Lilliehook et al. 2003; Rhodes et al. 2004). It is a multifunctional protein that acts as an interacting protein for $\mathrm{Kv} 4$ channels (An et al. 2000), a transcriptional repressor (Carrion et al. 1999), and a protein that interacts with

\section{A}
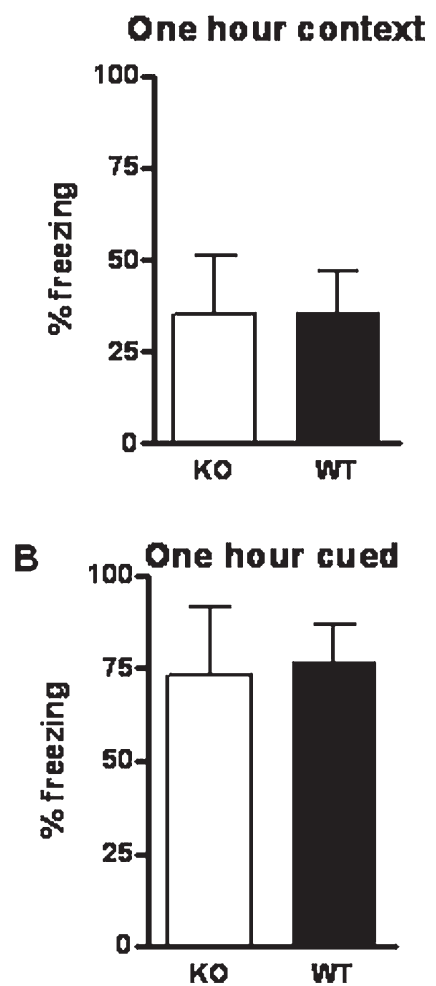

Figure 5. Male KChIP3 KO mice exhibited no differences in cued or contextual fear conditioning when tested $1 \mathrm{~h}$ after training. (A) A separate group of mice were tested for freezing in the context and to the cue $1 \mathrm{~h}$ after training. KChIP3 KO $(n=4)$, and WT littermates $(n=8)$ showed no differences in freezing levels in the context $(t$-test, $P>0.05)$ or $(B)$ the cued tests $(t$-test, $P>0.05)$ only $1 \mathrm{~h}$ after training. 


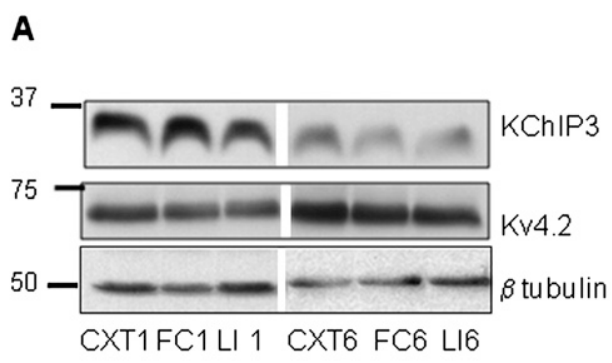

C

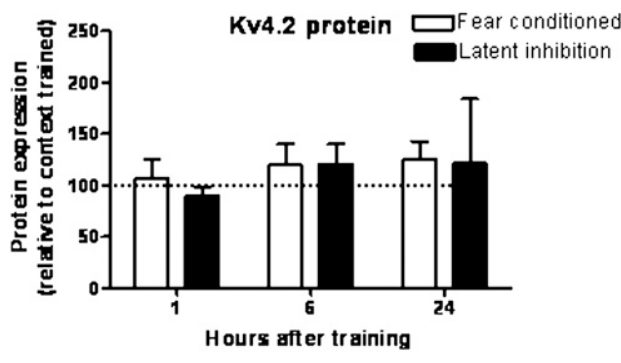

B

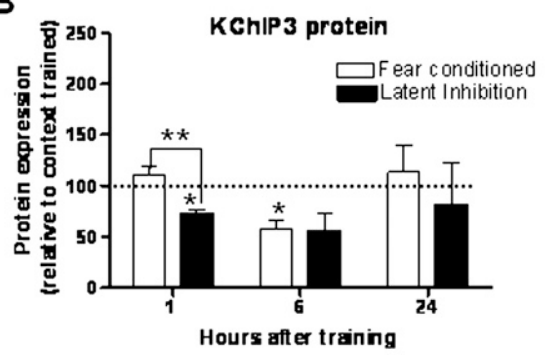

D

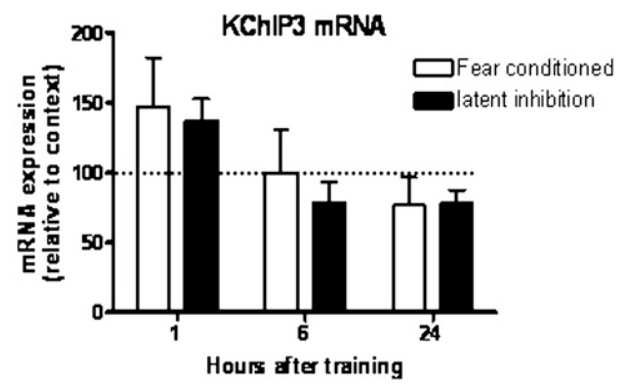

Figure 6. Changes in the immunoreactivity of hippocampus membrane expression levels of KChIP3, Kv4.2, and KChIP3 mRNA following fear conditioning in WT mice. Western blotting and real-time PCR were used to study expression of KChIP3 and Kv4.2 protein immunoreactivity as well as KChIP3 mRNA in the hippocampus at different time points $(1,6$, and $24 \mathrm{~h})$ following fear-conditioning training. Three groups of WT mice were trained as described in Materials and Methods: a context-trained group (CXT), a fear-conditioned group (FC), and a latent inhibition group (LI). ( $A$ ) Representative Western blots of membrane KChIP3 and Kv4.2 protein levels at 1- and 6-h time points in all three groups. (B) Bar graph summarizing immunoreactivity for KChIP3 membrane association at different time points after FC and LI training. KChIP3 membrane association in FC1 $(n=5)$ hippocampus was not significantly different from CXT1 $(n=5)$ at $1 \mathrm{~h}$ after training, but was significantly higher than LI1 (** $P<0.01, n=3$, which was significantly different from context, * $P<0.05$; One-Way ANOVA with post-hoc Tukey's test). KChIP3 membrane association was significantly decreased $(P<0.05) 6 \mathrm{~h}$ after FC training $(n=8)$ relative to CXT6 $(n=8)$. No significant differences between CXT24 $(n=3)$ and FC24 $(n=3)$ or LI24 $(n=3)$ were found at the 24-h time point. (C) Membrane Kv4.2 expression in the hippocampus at different time points after FC and LI training. There was no significant effect on immunoreactivity for Kv4.2 membrane expression at the 1-h time point $(P>0.05 ; \mathrm{FC1}, n=3, \mathrm{LI}, n=3, \mathrm{CXT1}, n=3), 6$-h time point $(P>0.05$; FC6, $n=5$, LI6, $n=5$, CXT6, $n=5)$, or 24-h time point ( $P>0.05$; FC24, $n=4$, LI24, $n=2$, CXT24, $n=4)$. (D) There was no difference in KChIP3 mRNA expression at any of the time points; 1 -h time point $(P>0.05 ; \mathrm{FC1}, n=3, \mathrm{LI} 1, n=3, \mathrm{CXT1}, n=3), 6$-h time point $(P>0.05 ; \mathrm{FC} 6, n=5, \mathrm{LI} 6, n=5)$, and $24 \mathrm{~h}$ time point $(P>0.05 ; \mathrm{FC} 24, n=3, \mathrm{LI} 24, n=3)$.

presenilin (Buxbaum et al. 1998). The role of KChIP3 in learning and memory could utilize any one or any combination of these mechanisms. In this study, we investigated its roles as a transcriptional repressor and $\mathrm{K}^{+}$channel interacting protein. We suggest that KChIP3 plays a role in consolidation of hippocampus-dependent fear memories through dissociation from the membrane, translocation to the nucleus, and regulation of gene transcription (Fig. 10).

We assessed the KChIP3 $\mathrm{KO}$ animals in terms of their baseline expression of other proteins known to interact with KChIP3 in its role as a $\mathrm{K}^{+}$channel interacting protein. Previous reports demonstrated that KChIP3 and KChIP2 expression levels are decreased in Kv4.2 KO mice (Chen et al. 2006; Menegola and Trimmer 2006), therefore we wished to determine if there was regulation of other KChIPs, Kv4.2, or Kv4.3 in the KChIP3 KO mouse. There was no significant effect of KChIP3 gene deletion on the expression levels of KChIP2, KChIP1, Kv4.2, or Kv4.3. This information suggests that KChIP3 does not regulate the total expression levels of these proteins in vivo, or that compensation by other KChIPs of Kv4 protein expression can substitute for the loss of KChIP3.

Interestingly, we found that KChIP3 KO mice exhibited enhanced memory in a contextual fear-conditioning paradigm that was long-lasting and present upon reactivation. When animals were tested again 1 mo later, the KO mice still showed enhanced freezing in the context. This is in contrast to no significant difference between the WT and KO mice on the cued fear-conditioning task. Furthermore, $\mathrm{KO}$ animals that were tested an hour after the training protocol froze at a similar level compared to WT mice. This suggests that there is no post-shock enhancement of anxiety in the KChIP3 KO mice and that KChIP3 does not play a role in memory acquisition. Cued fear conditioning is dependent on the amygdala, while the hippocampus is also important for contextual fear conditioning (Phillips and LeDoux 1992). This data do suggest that the KChIP3 KO mice exhibit enhanced memory in a hippocampus-dependent task and that KChIP3 may play a role in hippocampus-dependent memory consolidation.

Table 1. KChIP3 protein expression (as percentage of context)

\begin{tabular}{lccc}
\hline & $\mathbf{1} \mathbf{h}$ & $\mathbf{6 h}$ & $\mathbf{2 4} \mathbf{h}$ \\
\hline LI & $73 \pm 4 \% ; n=3$ & $56 \pm 16 \% ; n=4$ & $81 \pm 41 \% ; n=3$ \\
FC & $111 \pm 8 \% ; n=5$ & $58 \pm 7 \% ; n=8$ & $113 \pm 27 \% ; n=3$ \\
ANOVA & $F_{(2,9)}=10.35, P=0.005$ & $F_{(2,17)}=5.2, P=0.02$ & $F_{(2,6)}=0.48, P=0.64$ \\
\hline
\end{tabular}


Table 2. Kv4.2 protein expression (as percentage of context)

\begin{tabular}{lccc}
\hline & $\mathbf{1} \mathbf{h}$ & $\mathbf{6 h}$ & $\mathbf{2 4} \mathbf{h}$ \\
\hline LI & $84 \pm 8 \% ; n=3$ & $132 \pm 22 \% ; n=5$ & $122 \pm 62 \% ; n=2$ \\
FC & $106 \pm 19 \% ; n=3$ & $120 \pm 20 \% ; n=5$ & $125 \pm 18 \% ; n=4$ \\
ANOVA & $F_{(2,9)}=1.0, P=0.42$ & $F_{(2,12)}=0.52, P=0.61$ & $F_{(2,7)}=0.44 ; P=0.66$ \\
\hline
\end{tabular}

In our behavioral studies we found that the KChIP3 KO animals are slightly more anxious than their WT littermates, based on altered behavior in anxiety levels in the open field assessment. This increased anxiety, however, does not appear to underlie the enhancement of contextual fear conditioning for two reasons: (1) Prior to shock in the initial training period, KChIP3 KO and WT mice exhibited similar exploratory behavior; (2) a control experiment ruled out the possibility of a post-shock enhancement of freezing behavior as we tested a second group of animals $1 \mathrm{~h}$ after training in order to test for a post-shock anxiety enhancement. We found no differences between $\mathrm{WT}$ and $\mathrm{KO}$ in the cued or contextual tests $1 \mathrm{~h}$ after training. These data have several implications: First, KChIP3 KO animals exhibit similar exploratory behavior and post-shock motor behavior to WT animals, and secondly, the increased anxiety phenotype in the $\mathrm{KO}$ animal does not appear to affect fear conditioning. Furthermore, this effect was not due to an enhanced sensation of the foot shock as KO animals tested in the shock threshold paradigm did not differ from WT animals. Together, these data suggest that KChIP3 plays a role in associative contextual memory per se as opposed to altering baseline behaviors or altering training-associated sensory perception.

These experiments are consistent with previous data showing a decrease in the A-type current in dentate granule cells and enhanced LTP at the perforant path-dentate granule cell synapse in another strain of KChIP3 KO mice (Lilliehook et al. 2003). The enhanced memory of the context in the KChIP3 KO mice suggests that KChIP3 may play an inhibitory role in consolidation of fear memories. Therefore, we investigated possible mechanisms for KChIP3's role in contextual fear conditioning. Since KChIP3 is a multifunctional protein, several possibilities existed, including regulation of A-type currents and transcriptional regulation. In an attempt to determine KChIP3's role, we first investigated changes in membrane and nuclear KChIP3 localization after the fearconditioning training protocol.

Our data suggest a post-training regulation of Kv4.2 and KChIP3 association and that translocation to the nucleus may contribute to the role of KChIP3 in the hippocampus. Interestingly, a significant difference in KChIP3 membrane association $1 \mathrm{~h}$ after training was observed between FC and LI. This suggests a specific role for an increase in membrane KChIP3 association $1 \mathrm{~h}$ after FC training compared to LI. Furthermore, membrane KChIP3 expression is decreased $6 \mathrm{~h}$ after training (Fig. 6) and the KChIP3/ Kv4.2 interaction is diminished (Fig. 7), while nuclear KChIP3 is increased (Fig. 8). The membrane-associated KChIP3 decreased by approximately one-half (50\%) in both LI6 and FC6 compared to context. This suggests that membrane KChIP3 is decreased after both LI and FC training and a general role for down-regulation of membrane KChIP3 function. Furthermore, the nuclear expression of KChIP3 doubled at the 6-h time point after FC. This suggests that the membrane KChIP3 translocated to the nucleus. On the other hand, nuclear KChIP3 decreased by $\sim 50 \%$ in the LI-treated animals. This suggests an overall down-regulation and degradation of the KChIP3 protein in the LI-treated animals after training. To support this idea, KChIP3 mRNA is decreased, although not significantly, at the 6-h time point after LI, but remains stable in the FC-trained (Fig. 6D). Certainly, memories are formed in all situations including the context exploration, and the general decrease in membrane KChIP3 in FC-trained and LI-trained suggests that it is not specific to the associative FC-trained memory. The specific presence of KChIP3 in the nucleus after FC training does suggest a particular role for the nuclear translocation of KChIP3 in associative FC memory.

The function of the decrease in membrane KChIP3 and in the Kv4.2 and KChIP3 interaction is unknown but is expected to regulate A-type current and modulate cell excitability, possibly contributing to changes in plasticity. Depending on the role of KChIP3 in modulation of the A-type currents, this could either enhance or decrease cell excitability, and several possibilities exist. KChIPs are known to enhance A-type currents (for review, see Birnbaum et al. 2004) and a simple explanation is that less KChIP3 at the membrane would be expected to decrease A-type currents and enhance cell excitability. On the other hand, this decrease in KChIP3 at the membrane may actually decrease cell excitability. Recent data suggest that direct phosphorylation of $\mathrm{Kv} 4.2$ subunits by PKA causes internalization of the Kv4.2 channels (Hammond et al. 2008), which would result in a decrease in A-type current. We have shown that KChIP3 association is necessary for functional modulation of the current by PKA (Schrader et al. 2002); therefore, it is possible that, in the absence of association with KChIP3, PKA may not internalize the channels and hence increase A-type currents and decrease cell excitability. Yet another possibility exists with the discovery of the transmembrane KChIPs that may mediate differential effects on retention in the endoplasmic reticulum (Jerng and Pfaffinger 2008). In the future it will be interesting to determine whether the changes in KChIP3 membrane association at the

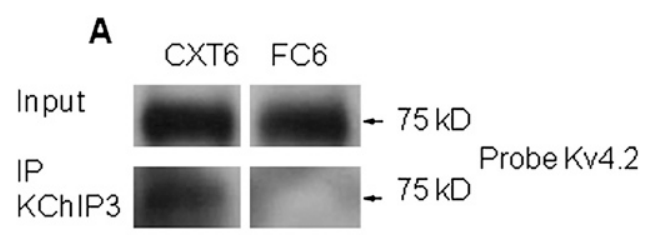

B

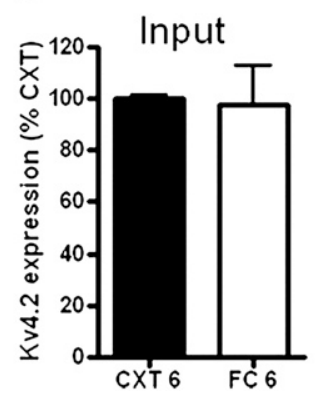

Figure 7. KChIP3 and Kv4.2 interaction is decreased $6 \mathrm{~h}$ after FC training relative to CXT. (A) Co-immunoprecipitation with KChIP3 antibody and probed with the Kv4.2 antibody shows that the Kv4.2 and KChIP3 interaction is diminished in the FC-trained animals relative to the CXT trained animals $(n=3)$. The exposure time for the Kv4.2 input was shorter than the exposure time for IP. (B) Summary bar graph showing that there was no difference in immunoreactivity of Kv4.2 expression measured in the input. 
A
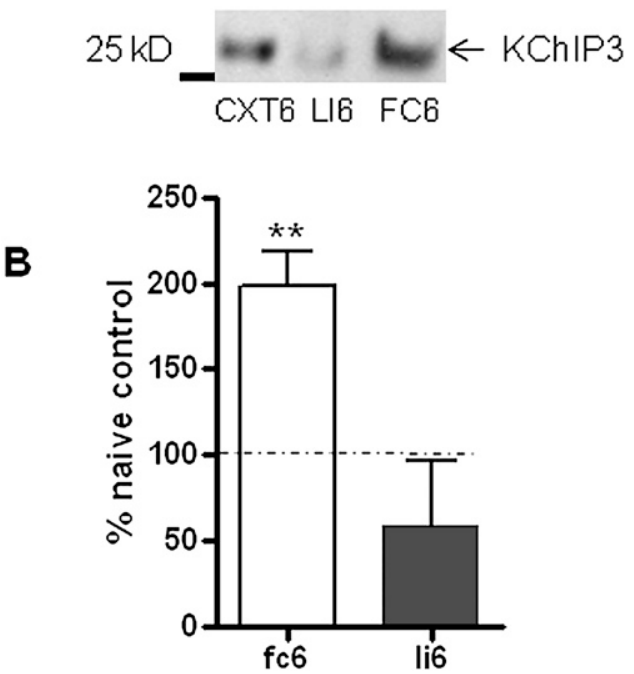

Figure 8. Levels of KChIP3 immunoreactivity are increased in the nucleus $6 \mathrm{~h}$ after FC training. Nuclear fractions were assayed for the presence of KChIP3 in the nucleus. (A) Representative Western blot of nuclear fraction with KChIP3 antibody from CXT6, LI6, and FC6 tissue. The KChIP3 antibody recognized a band in the nuclear fraction that was slightly smaller than the membrane KChIP3 band $(\sim 25 \mathrm{kDa}) .(B)$ Summary bar graph showing percent change in immunoreactivity for this band in the nucleus of FC6 and LI6 relative to CXT6. This band increased significantly in the nucleus at the 6-h time point in the FC-trained animals (One-Way ANOVA, ${ }^{*}, P<0.01 ; n=3$ ) relative to CXT $(n=3)$, but not in the Ll-trained $(P>0.05, n=3)$.

1- and 6-h time points regulate A-type potassium currents and neuronal excitability after fear-conditioning training.

We also determined whether a gene that KChIP3 regulates is modulated following fear conditioning. While KChIP3 regulates the expression of several genes (Link et al. 2004), we focused on regulation of prodynorphin since it is known to play a role in learning and memory. We found that prodynorphin expression was increased $1 \mathrm{~h}$ after training and decreased at the 6-h time point. Furthermore, prodynorphin mRNA is not modulated in KChIP3 KO mice $6 \mathrm{~h}$ after training. This suggests a role for KChIP3 in regulation of prodynorphin mRNA expression.

\section{Role of dynorphin in learning and memory}

The prodynorphin-derived peptide, dynorphin, and activation of the $\kappa$ opioid receptors both play a role in learning and memory. Dynorphin is thought to play a role in activity-dependent processes, including epilepsy (Simonato and Romualdi 1996) and learning and memory. Specifically, injection of dynorphin into the hippocampus of rats impaired spatial memory (McDaniel et al. 1990; Sandin et al. 1998). Dynorphin was increased in the hippocampus of aged animals and this increase is related to poor performance in spatial learning tasks in aged animals (Jiang et al. 1989). Moreover, aged mice lacking the prodynorphin gene showed improved spatial learning compared to WT. These data suggest that high levels of dynorphin in the hippocampus may lead to poor acquisition or recall of spatial memory. On the contrary, blockade of $\kappa$ opioid receptors reduced fear conditioning, suggesting that activation of the receptors by endogenous dynorphin facilitates fear conditioning (Fanselow et al. 1991). These opposing effects of exogenous application of dynorphin and inhibition of endogenous dynorphin suggest that control of dynorphin expression is very important for hippocampus-dependent memory. We show here that prodynorphin mRNA is regulated after fear-conditioning training by KChIP3. Interestingly, acute stressors increased dynorphin immunoreactivity in the hippocampus and nucleus accumbens (Shirayama et al. 2004), suggesting up-regulation of the dynorphin protein. The increase in prodynorphin mRNA at the 1-h time point after LI and FC that we observed (Fig. 9) may be related to the stress-induced enhancement of dynorphin.

\section{Specific role of dentate gyrus in memory}

KChIP3 is highly expressed in the dentate gyrus (Lilliehook et al. 2003; Rhodes et al. 2004). Furthermore, dentate granule cells from KChIP3 KO mice show decreased A-type current and enhanced LTP induction at the perforant path-dentate granule cell synapse (Lilliehook et al. 2003). We showed here that KChIP3 plays a role in hippocampus-dependent contextual fear conditioning.

Computational models of hippocampal function (Rolls and Kesner 2006), and now experimental data (McHugh et al. 2007), suggest that the dentate gyrus plays a role in encoding sensory inputs and spatial pattern separation as well as encoding spatial information and sending that information to CA3. The place fields of dentate granule cells are small and highly reliable (Jung and McNaughton 1993), which indicates the granule cells may play a role in separation of distinct environments and unique feature detection. Behavioral lesion studies have defined a role for the dentate gyrus (DG) in detecting novel environment but not object information (Kesner et al. 2004; Lee and Kesner 2004b; Lee et al. 2005), as well as retrieval of contextual fear-conditioning information (Lee and Kesner 2004a). Since KChIP3 is highly expressed in the dentate granule cells, the dentate is most likely where the effects are occurring. We demonstrated that KChIP3 disassociates from the membrane and translocates to the nucleus to regulate gene expression after fear conditioning. These studies implicate KChIP3 as an important molecular component of memoryassociated processes operating in the dentate gyrus.

\section{Materials and Methods}

\section{Generation of KChIP3 KO mice}

The KChIP3 KO mice were developed by Dr. W. Frank An through Lexicon. These animals were generated by targeted disruption of

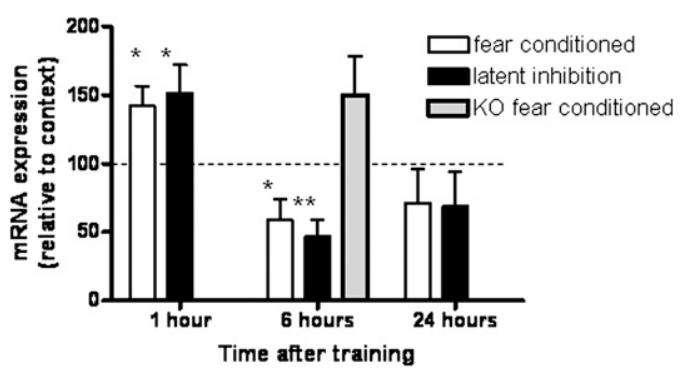

Figure 9. Prodynorphin mRNA levels in hippocampus following fear conditioning. Real-time PCR was used to determine if prodynorphin mRNA expression was regulated after FC training and LI training in WT mice. Prodynorphin mRNA was significantly decreased at the 6-h time point in both FC6 and LI6 hippocampus relative to CXT6 (One-Way ANOVA with post-hoc Tukey's test; FC6, $n=6, P<0.05$, LI6, $n=6, P<$ 0.01 ). Prodynorphin mRNA was also significantly increased at the 1 -h time point in both $\mathrm{FC} 1$ and $\mathrm{LI} 1$ relative to CXT1 (FC1, $n=3,142 \pm 15 \%, P$ $<0.05 ;$ LI1 $, n=3, P<0.05)$, and prodynorphin mRNA was decreased in both FC and LI at the 24-h time point, although not significantly (FC24, $n=$ 3 , LI24, $n=3 ; P>0.05$ ). Prodynorphin mRNA expression was also tested in KChIP3 KO mice $6 \mathrm{~h}$ after FC and CXT. Prodynorphin mRNA was not significantly modulated in the KChIP3 KO mice $6 \mathrm{~h}$ after FC training relative to CXT $(150 \pm 28 \%, n=6, P>0.05)$. 


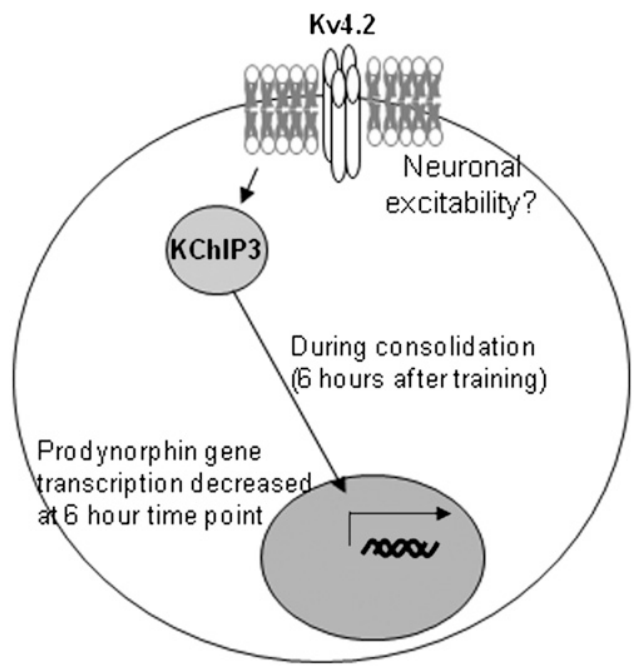

Figure 10. Schematic diagram of a proposed model for the role of KChIP3 in contextual fear conditioning. We propose that during consolidation (between 1 and $6 \mathrm{~h}$ after training) KChIP3 translocates from the membrane to the nucleus and regulates gene expression. We show that prodynorphin $\mathrm{mRNA}$ is regulated after training and $\mathrm{KChIP3}$ plays a role in this regulation.

exons 6-8 of the KChIP3/calsenilin/DREAM gene. The line was originally an F1:F1 hybrid between C57BL/6c-tyrx129S5/SvEvBrd and back-crossed twice on a 129 background. The mouse colony was maintained using a het $\times$ het breeding scheme. Littermate WT and $\mathrm{KO}$ male mice ages $6-12$ wk old were tested. All protocols followed the guidelines from the animal protocol approved by the Animal Care and Use Committee of Baylor College of Medicine, Tulane University and the University of Alabama at Birmingham and the guidelines of Ethical Conduct of Research from the NIH.

\section{Genotyping}

Littermate genotypes were confirmed by PCR results on the basis of WT or KO band. The specific primers used include: KChIP3 F: 5' CTGGGACATATTTGGAACAAGC-3', KChIP3 R: 5'-CTGCATACG CCCTAAGGAATAGAGC-3', and Neo 5'-CTGCAGCGCATCGCCT TCTATC-3'; WT product: 568 base pairs, KO product: 300 base pairs. Genotyped mice were confirmed WT or KO with Western blot. The researcher was blinded to the mouse genotype during testing.

\section{Preparation of tissue for Western blotting}

Mice were killed by decapitation and the brain carefully removed from the cranium and placed in oxygenated $\left(95 \% \mathrm{O}_{2} / 5 \% \mathrm{CO}_{2}\right)$ ice cold cutting solution in $\mathrm{mM}$ (110 Sucrose, $60 \mathrm{NaCl}, 3 \mathrm{KCl}, 0.5$ $\mathrm{CaCl}_{2}, 1.25 \mathrm{Na}_{2} \mathrm{HPO}_{4}, 28 \mathrm{NaHCO}_{3}, 0.6$ ascorbic acid, $7 \mathrm{MgCl}_{2}$, and 5 glucose; $\mathrm{pH} 7.4$, and osmolarity 305). Hippocampi were rapidly removed and frozen on dry ice. Tissue was processed into cytosol, nuclear, and membrane fractions according to the Compartmental Extraction Kit with added protease and phosphatase inhibitors (Chemicon). Protein assay was conducted on each sample and each fraction (DC protein assay, Biorad). Proteins were normalized across samples with the appropriate buffer. Sample buffer $(0.3 \mathrm{M}$ Tris, pH 6.8, 40\% glycerol, $8 \%$ SDS, and $150 \mathrm{mM}$ dithiothreitol [DTT]) was added, and the samples were stored at $-20^{\circ} \mathrm{C}$. Westerns with compartment specific antibodies (enolase: cytosol; Kv4.2: membrane; and histone 2: nuclear) were completed to confirm there was no contamination from other compartments in each fraction.

\section{Western blotting}

Proteins (20-50 $\mu \mathrm{g}$, depending on fraction and antibody used) were separated on $10 \%$ polyacrylamide gels and transferred to Immobilon-P membranes. Membranes were blocked and incubated with antisera (KChIP1, KChIP2, and KChIP3 monoclonal from Neuromab, Kv4.2 and Kv4.3 from Chemicon), typically diluted 1:1000, exposed to a horseradish peroxidase-linked antirabbit IgG (anti-mouse for monoclonals) secondary antibody diluted 1:20,000, and developed using an ECL kit (Amersham). Blots were stripped and reprobed for $\beta$ tubulin (Chemicon) as a loading control. Autoradiographs were quantified by digital densitometry using NIH Image J.

\section{Real-time PCR}

RNA was homogenized in PureZOL ${ }^{\mathrm{TM}}$ RNA isolation reagent from Biorad and total RNA was isolated according to the manufacturer's protocol. RNA was converted to cDNA using the iScript Select cDNA synthesis kit also from Biorad. cDNA was quantified using the Nanodrop 1000 and all samples were normalized to a concentration of $200 \mathrm{ng} / \mu \mathrm{L}$. The real-time PCR reaction was performed using Biorad's IQ SYBR Green Supermix in an ICycler from Biorad. Each well contained (in milliliters) Sybr Green Supermix (12.5), forward primers $(10 \mathrm{mM})(1)$, reverse primers $(10 \mathrm{mM})(1)$, DEPCtreated $\mathrm{H}_{2} \mathrm{O}(12.5)$, and cDNA $(200 \mathrm{ng} / \mu \mathrm{L})(1)$. All reactions were performed in triplicate. The specific primers used to amplify prodynorphin from cDNA were (F): 5'-AGTGGAGATCCCCTGCC AA-3', (R): 5'-AGAGCCTCTGTGGCTGAGA-3'; KChIP3 (F): 5'-AGT GACAATTGCGTCTGGGTC-3', (R) 5'-ATGGCGCACCGTGGATA AC-3' housekeeping genes, $18 \mathrm{~S}$ rRNA (F: 5'-TCAAGAACGAAAGTC GGAGG-3', R: 5'-GGACATCTAAGGGCATCACA-3') and GAPDH (F: 5'-AATGTGTCCGTCGTGGATCTG-3', R: 5'-AGAGTGGGAGTTGC TGTTGAAG-3'). Genes of interest (KChIP3 and prodynorphin) were normalized to $18 \mathrm{~S}$ rRNA for all samples reported. Changes in the fearconditioned and latent inhibition time points are normalized to the context trained at the same time point.

\section{Fear-conditioning protocol}

The experimenter was blinded to the genotype of animals during all behavioral experiments. KChIP3 WT and KChIP3 KO littermate controls were tested on cued and contextual fear-conditioning paradigms. Both naïve mice (mice that had not previously been tested in a behavioral test) and mice that had previously experienced other tests (OFA, elevated plus, and rotarod-several days to one week between tests) were tested. There was no significant difference in the results, therefore the data were combined. Mice were trained in a single-shock protocol. An animal was placed in a chamber and allowed to freely explore the chamber. After $120 \mathrm{sec}$ an $80 \mathrm{~dB}$ white noise cue commenced for $30 \mathrm{sec}$. The cue coterminated with a single mild foot shock $(0.50 \mathrm{~mA})$ for $2 \mathrm{sec}$. The mouse was left to explore the chamber for an additional $90 \mathrm{sec}$. Different mice were tested $1 \mathrm{~h}$ or $24 \mathrm{~h}$ following training on the cued and contextual tests. Contextual testing consisted of analysis of freezing time in the same context for 240 sec. For the cued test the mice were placed in a unique context and allowed to freely explore the new context. After $180 \mathrm{sec}$ the white noise cue commenced. Freezing was measured during the $180 \mathrm{sec}$ of the cue. The percent freezing to both the context and cued paradigms was analyzed for each mouse via Med Associates software. Some animals were independently observed by a blinded scorer.

\section{Rotarod protocol}

Mice were placed onto a horizontal rod, $\sim 3 \mathrm{~cm}$ in diameter. The rotarod accelerated from 4 to $40 \mathrm{rpm}$ during the course of the 5 -min trial. The amount of time that an animal spent on the rod, before drop ( $\sim 12 \mathrm{~cm}$ onto a rest platform) to a maximum of $5 \mathrm{~min}$, was determined. The animal was then returned to the home cage, and rod and rest platforms were cleaned with ethanol and water. Each animal was tested for four trials per day for two consecutive days. The animals rested in their home cages for $0.5-1 \mathrm{~h}$ between each trial. Total time spent on the rod was determined for each trial. Time spent on the rod per trial was averaged across genotype and plotted per trial.

\section{Open field protocol}

A single mouse was placed in the center of a clear, plexiglass chamber measuring $43 \times 43 \times 18 \mathrm{~cm}$. The animal was left in the 
chamber for $15 \mathrm{~min}$ to explore the novel environment, and was monitored by a computer program (Versamax). After $15 \mathrm{~min}$, the animal was removed from the chamber and returned to its home cage. The plexiglass chamber was then wiped clean with ethanol and water before the next trial. Total movements as well as center/ total distance ratio were reported.

\section{Elevated plus maze protocol}

The elevated plus maze (EPM) consisted of four arms $(5 \mathrm{~cm} \times 30$ $\mathrm{cm}$ ) arranged perpendicularly in a plus shape and elevated $38 \mathrm{~cm}$ off of the ground. Two arms were enclosed by $15.5-\mathrm{cm}$ dark plexiglass walls and two arms were open. The subject animal was placed in the center of the elevated maze. The mouse was free to move into open or closed arms. An observer, blinded to genotype, recorded activity and time spent in the enclosed arms and the time required for the mouse to move to the open arm of the maze. At the end of the experimental trial (10 $\mathrm{min})$, the animal was lifted from the maze and returned into its home cage. Each mouse was tested once.

\section{Shock threshold}

Mice were tested in a range of foot shocks (0.1-0.7 mA in 0.1 increments) to determine sensitivity to the foot shock. Animals were scored on their response, including running, jumping, and vocalization. The response was assigned a numerical score by a blinded observer. The following scale was used: 0 , no response; 1 , move; 2 , vocalize; 3 , run; 4 , jump; 5 , maximum response (vocalize, jump, and run).

\section{Fear-conditioning protocol for biochemistry}

WT male mice were trained using the same fear-conditioning protocol as before. Three groups of mice, a context-trained group (CXT), a fear-conditioned group (FC), and a latent inhibition group (LI) were sacrificed at various time points after training. The context-trained mice were placed in the chamber for $4 \mathrm{~min}$ but did not receive a foot shock. The fear-conditioned mice were trained using the 4-min, single-shock protocol as described above for behavioral fear conditioning. The latent inhibition mice were placed in the chamber and were allowed to explore for $2 \mathrm{~h}$ before receiving a single foot shock. The mice for these experiments were only trained and not tested. Following training the mice were then sacrificed at 1, 6, and $24 \mathrm{~h}$ later and their hippocampi removed and frozen for biochemistry at a later date. Data were normalized to the levels of expression of the given protein or mRNA in the animals that only experienced context at each time point. Results at each time point were compared between CXT, LI, and FC using a one-way ANOVA and post-hoc Tukey's test.

\section{Co-immunoprecipitation}

Co-immunoprecipitation reactions were performed at room temperature (RT) using the normalized membrane fraction from the Chemicon fractionation kit (as described above) from the whole hippocampus (CXT6 and FC6). Affinity-purified mouse monoclonal antibody specific for KChIP3 (Neuromab) were added into the reaction tube and incubated at RT for $2 \mathrm{~h}$ on a rocker. A $50 \%$ slurry of protein A agarose (Pierce) was added to the tube, and the samples were incubated at RT for another $2 \mathrm{~h}$ on a rocker. After incubation, protein A agarose was centrifuged at $2500 \mathrm{~g}$ for $3 \mathrm{~min}$, and the resulting pellets were washed by resuspension and centrifuged three times with IP buffer (Pierce). The final pellets were resuspended in $30 \mu \mathrm{L}$ of elution buffer, incubated for $5 \mathrm{~min}$, and centrifuged at $2500 \mathrm{~g}$ for $3 \mathrm{~min}$. Supernatant was saved and the step was repeated. Supernatants were combined in the same tube. For neutralization, $6 \mu \mathrm{L} 1 \mathrm{M}$ Tris- $\mathrm{HCl} \mathrm{pH} 7.5$ was added. Finally, samples were prepared for Western blots by adding $100 \mathrm{mM}$ DTT and $15 \mu \mathrm{L} 5 \times$ nonreducing sample buffer and heated at $50^{\circ} \mathrm{C}$ for $10 \mathrm{~min}$.

\section{Acknowledgments}

This work was supported by grants MH064620, MH57014, NS37444, NS057098, NS013546, NARSAD, and the Evelyn F. McKnight Brain Research Foundation. We also acknowledge support by grants from the NIH/NIMH MH064620 to L.A.S. and NS37444 to J.D.S. We thank Dan Liu and Duy Bui for technical support. The content of this work is the sole responsibility of the authors and does not necessarily represent the official view of the National Institute of Neurological Disorders and Stroke, the National Institute of Mental Health, or the National Institutes of Health.

\section{References}

An, W.F., Bowlby, M.R., Betty, M., Cao, J., Ling, H.P., Mendoza, G., Hinson, J.W., Mattsson, K.I., Strassle, B.W., Trimmer, J.S., et al. 2000. Modulation of A-type potassium channels by a family of calcium sensors. Nature 403: $553-556$.

Bahring, R., Dannenberg, J., Peters, H.C., Leicher, T., Pongs, O., and Isbrandt, D. 2001. Conserved Kv4 N-terminal domain critical for effects of $\mathrm{Kv}$ channel-interacting protein 2.2 on channel expression and gating. J. Biol. Chem. 276: 23888-23894.

Birnbaum, S.G., Varga, A.W., Yuan, L.L., Anderson, A.E., Sweatt, J.D., and Schrader, L.A. 2004. Structure and function of Kv4-family transient potassium channels. Physiol. Rev. 84: 803-833.

Boland, L.M., Jiang, M., Lee, S.Y., Fahrenkrug, S.C., Harnett, M.T., and O'Grady, S.M. 2003. Functional properties of a brain-specific NH2terminally spliced modulator of Kv4 channels. Am. J. Physiol. Cell Physiol. 285: C161-C170.

Burgoyne, R.D. and Weiss, J.L. 2001. The neuronal calcium sensor family of $\mathrm{Ca}^{2+}$-binding proteins. Biochem. J. 353: 1-12.

Buxbaum, J.D., Choi, E.K., Luo, Y., Lilliehook, C., Crowley, A.C., Merriam, D.E., and Wasco, W. 1998. Calsenilin: A calcium-binding protein that interacts with the presenilins and regulates the levels of a presenilin fragment. Nat. Med. 4: 1177-1181.

Carrion, A.M., Link, W.A., Ledo, F., Mellstrom, B., and Naranjo, J.R. 1999. DREAM is a $\mathrm{Ca}^{2+}$-regulated transcriptional repressor. Nature 398: 80-84

Chen, X., Yuan, L.L., Zhao, C., Birnbaum, S.G., Frick, A., Jung, W.E., Schwarz, T.L., Sweatt, J.D., and Johnston, D. 2006. Deletion of Kv4.2 gene eliminates dendritic A-type $\mathrm{K}^{+}$current and enhances induction of long-term potentiation in hippocampal CA1 pyramidal neurons. $J$. Neurosci. 26: 12143-12151.

Cheng, H.Y., Pitcher, G.M., Laviolette, S.R., Whishaw, I.Q., Tong, K.I., Kockeritz, L.K., Wada, T., Joza, N.A., Crackower, M., Goncalves, J., et al. 2002. DREAM is a critical transcriptional repressor for pain modulation. Cell 108: 31-43.

Choi, E.K., Miller, J.S., Zaidi, N.F., Salih, E., Buxbaum, J.D., and Wasco, W. 2003. Phosphorylation of calsenilin at Ser63 regulates its cleavage by caspase-3. Mol. Cell. Neurosci. 23: 495-506.

Fanselow, M.S., Kim, J.J., Young, S.L., Calcagnetti, D.J., DeCola, J.P., Helmstetter, F.J., and Landeira-Fernandez, J. 1991. Differential effects of selective opioid peptide antagonists on the acquisition of Pavlovian fear conditioning. Peptides 12: 1033-1037.

Frick, A., Magee, J., and Johnston, D. 2004. LTP is accompanied by an enhanced local excitability of pyramidal neuron dendrites. Nat. Neurosci. 7: 126-135.

Hammond, R.S., Lin, L., Sidorov, M.S., Wikenheiser, A.M., and Hoffman, D.A. 2008. Protein kinase A mediates activity-dependent Kv4.2 channel trafficking. J. Neurosci. 28: 7513-7519.

Hoffman, D.A. and Johnston, D. 1998. Down-regulation of transient $\mathrm{K}^{+}$ channels in dendrites of hippocampal CA1 pyramidal neurons by activation of PKA and PKC. J. Neurosci. 18: 3521-3528.

Hoffman, D.A., Magee, J.C., Colbert, C.M., and Johnston, D. 1997. K channel regulation of signal propagation in dendrites of hippocampal pyramidal neurons. Nature 387: 869-875.

Holmqvist, M.H., Cao, J., Hernandez-Pineda, R., Jacobson, M.D., Carroll, K.I., Sung, M.A., Betty, M., Ge, P., Gilbride, K.J., Brown, M.E., et al. 2002. Elimination of fast inactivation in Kv4 A-type potassium channels by an auxiliary subunit domain. Proc. Natl. Acad. Sci. 99: 1035-1040.

Itoh, J., Nabeshima, T., and Kameyama, T. 1991. Utility of an elevated plus maze for dissociation of amnesic and behavioral effects of drugs in mice. Eur. J. Pharmacol. 194: 71-76.

Jerng, H.H. and Pfaffinger, P.J. 2008. Multiple Kv channel-interacting proteins contain an N-terminal transmembrane domain that regulates Kv4 channel trafficking and gating. J. Biol. Chem. 283: 36046-36059.

Jerng, H.H., Kunjilwar, K., and Pfaffinger, P.J. 2005. Multiprotein assembly of Kv4.2, KChIP3 and DPP10 produces ternary channel complexes with ISA-like properties. J. Physiol. 568: 767-788.

Jiang, H.K., Owyang, V.V., Hong, J.S., and Gallagher, M. 1989. Elevated dynorphin in the hippocampal formation of aged rats: Relation to cognitive impairment on a spatial learning task. Proc. Natl. Acad. Sci. 86: 2948-2951.

Jung, M.W. and McNaughton, B.L. 1993. Spatial selectivity of unit activity in the hippocampal granular layer. Hippocampus 3: 165-182. 
Kesner, R.P., Lee, I., and Gilbert, P. 2004. A behavioral assessment of hippocampal function based on a subregional analysis. Rev. Neurosci. 15: 333-351.

Kim, L.A., Furst, J., Butler, M.H., Xu, S., Grigorieff, N., and Goldstein, S.A. 2004. Ito channels are octomeric complexes with four subunits of each Kv4.2 and $\mathrm{K}^{+}$channel-interacting protein 2. J. Biol. Chem. 279: 55495554.

Kim, J., Wei, D.S., and Hoffman, D.A. 2005. Kv4 potassium channel subunits control action potential repolarization and frequencydependent broadening in rat hippocampal CA1 pyramidal neurones. J. Physiol. 569: 41-57.

Kim, J., Jung, S.C., Clemens, A.M., Petralia, R.S., and Hoffman, D.A. 2007. Regulation of dendritic excitability by activity-dependent trafficking of the A-type $\mathrm{K}^{+}$channel subunit Kv4.2 in hippocampal neurons. Neuron 54: $933-947$

Kulkarni, S.K. and Sharma, A.C. 1991. Elevated plus-maze: A novel psychobehavioral tool to measure anxiety in rodents. Methods Find. Exp. Clin. Pharmacol. 13: 573-577.

Lee, I. and Kesner, R.P. 2004a. Differential contributions of dorsal hippocampal subregions to memory acquisition and retrieval in contextual fear-conditioning. Hippocampus 14: 301-310.

Lee, I. and Kesner, R.P. 2004b. Encoding versus retrieval of spatial memory: Double dissociation between the dentate gyrus and the perforant path inputs into CA3 in the dorsal hippocampus. Hippocampus 14: 66-76.

Lee, I., Hunsaker, M.R., and Kesner, R.P. 2005. The role of hippocampal subregions in detecting spatial novelty. Behav. Neurosci. 119: 145-153.

Levenson, J.M., O'Riordan, K.J., Brown, K.D., Trinh, M.A., Molfese, D.L., and Sweatt, J.D. 2004. Regulation of histone acetylation during memory formation in the hippocampus. J. Biol. Chem. 279: 40545-40559.

Lilliehook, C., Bozdagi, O., Yao, J., Gomez-Ramirez, M., Zaidi, N.F., Wasco, W., Gandy, S., Santucci, A.C., Haroutunian, V., Huntley, G.W., et al. 2003. Altered $A^{\beta}$ formation and long-term potentiation in a calsenilin knock-out. J. Neurosci. 23: 9097-9106.

Link, W.A., Ledo, F., Torres, B., Palczewska, M., Madsen, T.M., Savignac, M., Albar, J.P., Mellstrom, B., and Naranjo, J.R. 2004. Day-night changes in downstream regulatory element antagonist modulator/potassium channel interacting protein activity contribute to circadian gene expression in pineal gland. J. Neurosci. 24: 5346-5355.

McDaniel, K.L., Mundy, W.R., and Tilson, H.A. 1990. Microinjection of dynorphin into the hippocampus impairs spatial learning in rats. Pharmacol. Biochem. Behav. 35: 429-435.

McHugh, T.J., Jones, M.W., Quinn, J.J., Balthasar, N., Coppari, R., Elmquist, J.K., Lowell, B.B., Fanselow, M.S., Wilson, M.A., and Tonegawa, S. 2007. Dentate gyrus NMDA receptors mediate rapid pattern separation in the hippocampal network. Science 317: 94-99.

Menegola, M. and Trimmer, J.S. 2006. Unanticipated region- and cellspecific downregulation of individual KChIP auxiliary subunit isotypes in Kv4.2 knock-out mouse brain. J. Neurosci. 26: 12137-12142.

Morohashi, Y., Hatano, N., Ohya, S., Takikawa, R., Watabiki, T., Takasugi, N., Imaizumi, Y., Tomita, T., and Iwatsubo, T. 2002. Molecular cloning and characterization of CALP/KChIP4, a novel EF-hand protein interacting with presenilin 2 and voltage-gated potassium channel subunit Kv4. J. Biol. Chem. 277: 14965-14975.
Patel, S.P., Campbell, D.L., Morales, M.J., and Strauss, H.C. 2002. Heterogeneous expression of KChIP2 isoforms in the ferret heart. J. Physiol. 539: 649-656.

Patel, S.P., Parai, R., and Campbell, D.L. 2004. Regulation of Kv4.3 voltagedependent gating kinetics by KChIP2 isoforms. J. Physiol. 557: 19-41.

Phillips, R.G. and LeDoux, J.E. 1992. Differential contribution of amygdala and hippocampus to cued and contextual fear conditioning. Behav. Neurosci. 106: 274-285.

Rhodes, K.J., Carroll, K.I., Sung, M.A., Doliveira, L.C., Monaghan, M.M., Burke, S.L., Strassle, B.W., Buchwalder, L., Menegola, M., Cao, J., et al. 2004. KChIPs and Kv $4 \alpha$ subunits as integral components of A-type potassium channels in mammalian brain. J. Neurosci. 24: 7903-7915.

Rolls, E.T. and Kesner, R.P. 2006. A computational theory of hippocampal function, and empirical tests of the theory. Prog. Neurobiol. 79: 1-48.

Sandin, J., Nylander, I., Georgieva, J., Schott, P.A., Ogren, S.O., and Terenius, L. 1998. Hippocampal dynorphin B injections impair spatial learning in rats: A к-opioid receptor-mediated effect. Neuroscience 85: 375-382.

Scannevin, R.H., Wang, K., Jow, F., Megules, J., Kopsco, D.C., Edris, W. Carroll, K.C., Lu, Q., Xu, W., Xu, Z., et al. 2004. Two N-terminal domains of $\mathrm{Kv} 4 \mathrm{~K}^{+}$channels regulate binding to and modulation by KChIP1. Neuron 41: 587-598.

Schrader, L.A., Anderson, A.E., Mayne, A., Pfaffinger, P.J., and Sweatt, J.D. 2002 PKA modulation of Kv4.2-encoded A-type potassium channels requires formation of a supramolecular complex. J. Neurosci. 22: 10123-10133.

Shibata, R., Misonou, H., Campomanes, C.R., Anderson, A.E., Schrader, L.A., Doliveira, L.C., Carroll, K.I., Sweatt, J.D., Rhodes, K.J., and Trimmer, J.S. 2003. A fundamental role for KChIPs in determining the molecular properties and trafficking of Kv4.2 potassium channels. $J$. Biol. Chem. 278: 36445-36454.

Shirayama, Y., Ishida, H., Iwata, M., Hazama, G.I., Kawahara, R., and Duman, R.S. 2004. Stress increases dynorphin immunoreactivity in limbic brain regions and dynorphin antagonism produces antidepressant-like effects. J. Neurochem. 90: 1258-1268.

Simonato, M. and Romualdi, P. 1996. Dynorphin and epilepsy. Prog. Neurobiol. 50: 557-583.

Van Hoorick, D., Raes, A., Keysers, W., Mayeur, E., and Snyders, D.J. 2003. Differential modulation of Kv4 kinetics by KCHIP1 splice variants. Mol. Cell. Neurosci. 24: 357-366.

Weiss, S.M., Lightowler, S., Stanhope, K.J., Kennett, G.A., and Dourish, C.T. 2000. Measurement of anxiety in transgenic mice. Rev. Neurosci. 11: 59-74.

Yuan, L.L., Adams, J.P., Swank, M., Sweatt, J.D., and Johnston, D. 2002. Protein kinase modulation of dendritic $\mathrm{K}^{+}$channels in hippocampus involves a mitogen-activated protein kinase pathway. J. Neurosci. 22: 4860-4868.

Zaidi, N.F., Berezovska, O., Choi, E.K., Miller, J.S., Chan, H., Lilliehook, C., Hyman, B.T., Buxbaum, J.D., and Wasco, W. 2002. Biochemical and immunocytochemical characterization of calsenilin in mouse brain. Neuroscience 114: 247-263.

Zhou, W., Qian, Y., Kunjilwar, K., Pfaffinger, P.J., and Choe, S. 2004. Structural insights into the functional interaction of KChIP1 with Shaltype $\mathrm{K}^{+}$channels. Neuron 41: 573-586.

Received October 16, 2008; accepted in revised form December 22, 2008. 


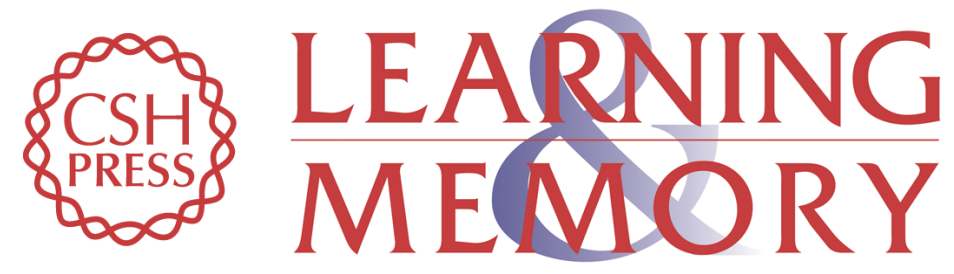

\section{The role of calsenilin/DREAM/KChIP3 in contextual fear conditioning}

Jon C. Alexander, Carmel M. McDermott, Tumay Tunur, et al.

Learn. Mem. 2009, 16:

Access the most recent version at doi:10.1101//m.1261709

References This article cites 52 articles, 17 of which can be accessed free at:

http://learnmem.cshlp.org/content/16/3/167.full.html\#ref-list-1

License

Email Alerting Receive free email alerts when new articles cite this article - sign up in the box at the Service top right corner of the article or click here. 